\title{
Management of Preeclampsia in Perioperative Conditions
}

\section{Yavuz Demiraran and Melike Korkmaz Toker}

Istanbul Kanuni Sultan Suleyman Research and Training Hospital Anesthesiology and Reanimation Clinic, Istanbul, Turkey

*Corresponding author: Melıke Korkmaz Toker, Kanuni Sultan Süleyman Research and Training Hospital, Anesthesia and Reanimation Clinic, Turkey, Tel: 00905054747098; E-mail: meltoker@gmail.com

Rec date: November 20, 2014 Acc date: October 19, 2015 Pub date: October 23, 2015

Copyright: (c) 2015 Demiraran Y, et al. This is an open-access article distributed under the terms of the Creative Commons Attribution License, which permits unrestricted use, distribution, and reproduction in any medium, provided the original author and source are credited.

\begin{abstract}
Anaesthetists are the key member of a multidisciplinary team providing management to a preeclamptic patient. Anaesthetist's responsibility starts before the surgery at the moment of stabilising patient's hemodynamic status and guiding to an obstetrician about administration of antihypertensives and seizure prophylaxis. Recent literature about antihypertensives and seizure prophylaxis is reviewed. Labetolol, hydralazine, diazoxide and nifedipine is considered as the most common used drugs and their dosage is revised in the light of the recent literatures. Magnesium sulphate is the most effective agent for seizure prophylaxis. Platelet transfusion threshold is determined as $50000 / \mathrm{mm}^{3}$ in acutely bleeding patient. We discussed the advantages and limitations of spinal anesthesia in the setting of severe preeclampsia. We emphasized the difficulties encountered in general anesthesia. The benefits of neuroaxial anesthesia in labour are well established. Potential maternal life-threating complications include acute pulmonary edema, oliguria and acute renal failure, intracranial hemorrhagies and stroke and also the treatment options in intensive care unit at the postnatal period is summarized. Plasmapheresis is discussed as an alternative successful treatment option in preeclamptic patients whose platelet consumption persisted after delivery.
\end{abstract}

Keywords: Preeclampsia; Anesthesia

\section{Introduction}

Preeclampsia, along with the other hypertensive disorders of pregnancy is a leading cause of maternal morbidity and mortality [1]. Preeclampsia affects the 5-8\% of all pregnancies worldwide [2]. Deaths are due to intracranial haemorrhage, respiratory failure and hepatic failure or rupture $[2,3]$.

Pre-eclampsia is generally defined as new hypertension (systolic blood pressure $\geq 140 \mathrm{mmHg}$ diastolic blood pressure of $\geq 90 \mathrm{~mm} \mathrm{Hg}$ ) and substantial proteinuria ( $\geq 300 \mathrm{mg}$ in $24 \mathrm{~h}$ ) at or after 20 weeks of gestation [4]. Eclampsia is defined as the occurrence of one or more generalized convulsions and/or coma in the setting of preeclampsia and in the absence of other neurologic conditions before, during, or after labour [5]. Risk factors are defined as genetic and familial factors (angiotensin T-235), chronic renal failure, preexisting hypertension, anticardiolipin syndrome, multiple pregnancies, elder pregnants and diabetes by the American College of Obstetrics and Gynecologists [6].

Pathophysiology of preeclampsia is associated with fetoplacental unit [7]. It is clear that abnormal placentation (development and arrangement of the placenta) and placental function are strong predisposing factors for preeclampsia. The effects of preeclampsia consist of uteroplacental hypoxia, an imbalance in angiogenic and antiangiogenic proteins, oxidative stress, maternal endothelial dysfunction, and elevated systemic inflammation [8]. Severe vasoconstriction causes endothelial cell injury, tromboxan A2 levels increase and coagulation cascade activates. As a result of this cascade fibrin deposits accumulation in the vessels, blood flow to fetoplacental unit and all maternal organs decrease. This causes to ischemia in entire body [7].

\section{Effects of Preeclampsia on Organ Systems}

Maternal organ systems that are susceptible to excessive inflammation and endothelial damage are the CNS, lungs, liver, kidneys, systemic vasculature, coagulation, and the heart.

\section{Cardiovascular Changes}

Bosio et al. [9] conducted a longitudinal study of 400 primigravidas who were monitored throughout pregnancy using Doppler echocardiography. Preeclampsia developed in 20 of the patients. Women who had preeclampsia had significantly elevated cardiac outputs before clinical diagnosis, but total peripheral resistance was not significantly different during this latent phase. During the clinical phase of preeclampsia, there was a marked reduction in cardiac output and increase in peripheral resistance. Belfort et al. [10] reported decreased pulmoner capillary wedge pressure and elevated systemic vascular resistance in thirty-two patients with severe preeclampsia (blood pressure $>160 / 110 \mathrm{~mm} \mathrm{Hg} 33$ to $4+$ proteinuria) who were monitored with a pulmonary artery catheter. In preeclampsia, both a hyperdynamic state with high cardiac output and low vascular resistance and a hypodynamic state with high resistances, low cardiac output and low plasma volume are described. These differences in haemodynamics have been recently ascribed to two different disease entities. Early-onset preeclampsia before 34 weeks of gestation is characterized by high resistance and low cardiac output, whereas late onset preeclampsia is dominated by high cardiac output and low vascular resistance [11].

\section{Central Nervous System}

Hypertension above the normal cerebral autoregulation pressure causes an increase in cerebral blood flow that prompts cerebral haemorrhage. The detachment in blood brain barrier raises the interstitial edema. Cerebral vasospasm, ischemia, edema, hemorrhage, 
and hypertensive encephalopathy are probably associated in the pathogenesis of eclampsia [12]. Although uncommon, temporary blindness also may accompany severe preeclampsia and eclampsia. Other nervous system manifestations include headache, blurred vision, scotomata, and hyperreflexia [13].

\section{Hematologic System}

Preeclampsia is commonly responsible for thrombocytopenia occurring in the 2nd and 3rd trimester. Roughly $20-50 \%$ of women with preeclampsia will develop thrombocytopenia and although thrombocytopenia is occasionally the sole manifestation of preeclampsia, the severity of thrombocytopenia typically parallels the underlying preeclampsia. Less than $5 \%$ of preeclamptic women will develop severe thrombocytopenia (platelets $<50,000 / \mathrm{uL}$ ) making the use of platelet transfusions rarely necessary [14].

The HELLP syndrome occurs in 10\% of women with preeclampsia and is characterized by Hemolysis, Elevated Liver enzymes and Low Platelets. The microangiopathic hemolytic anemia, elevated lactate dehydrogenase $(\mathrm{LDH}>600 \mathrm{U} / \mathrm{mL})$, increased aspartate aminotransferase $(\geq 70 \mathrm{U} / \mathrm{mL})$ and thrombocytopenia (platelets $<100,000 / \mathrm{uL}$ ) helps to identify this entity in women with preeclampsia [15].

\section{Hepatic System}

Hepatic functions significantly altered in women with severe preeclampsia. Alanine aminotransferase and aspartate aminotransferase may be elevated. Hyperbilirubinemia may occur, especially in the presence of hemolysis. Hepatic hemorrhage, which usually manifests as a subcapsular hematoma, also may occur, especially in women with preeclampsia and upper abdominal pain. Rarely, hepatic rupture, which is associated with a high mortality rate, occurs.

Gracia et al. [16] reviewed case reports of hepatic hematoma and rupture in women with pre-eclampsia and eclampsia between 1990 and 2010 on the MEDLINE, SciELO, and LILACS databases. 12 (6.7\%) of 180 cases of hepatic hematoma or rupture were associated with eclampsia plus HELLP syndrome were identified.

\section{Renal System}

Both renal blood, effective renal blood flow and GFR decrease in preeclampsia. Increased proteinuria is a hallmark of the preeclamptic syndrome, those preeclamptic patients also facing vasoconstriction plus enhanced vascular reactivity, and glomerular endothelial swelling producing capillary obstruction lead to postglomerular ischemia and acute tubular necrosis [17].

\section{Management of Care}

Multidisiplinary team approach has been emphasised in many recent publications $[18,19]$. Involving the anaesthetist to the team is an important step for providing the preeclamptic patient's stabilisation before delivery. The basis of the management of pre-eclampsia is antihypertensive therapy, seizure prophylaxis, facilitated delivery and critical care management.

\section{Antihypertensive Therapy}

When the diagnosis is preeclampsia, the gestational age, as well as the level of BP, influences the use of antihypertensive therapy. At term, women with preeclampsia are likely to be delivered, treatment of hypertension (unless severe) can be delayed, and BP can be reevaluated postpartum. If preeclampsia develops remote from term, and expectant management is undertaken, treatment of severe hypertension is initiated, and BP can usually be safely lowered to $140 / 90 \mathrm{~mm} \mathrm{Hg}$ with oral medications as methyldopa, labetalol, nifedipine or isradipine, and some $\beta$-adrenoceptor blockers (metoprolol, pindolol, and propranolol) and low dose diazoxide [20].

It should be emphasized that there are no studies addressing safe BP treatment targets for pregnant women, and guidelines and reviews generally recommend treating to $\mathrm{BP}$ levels that are likely to be protective against acute adverse cerebrovascular or cardiovascular events, which is usually in the range of 140 to $155 / 90$ to $105 \mathrm{~mm} \mathrm{Hg}$ [21]. When antihypertensive therapy is used in women with preeclampsia, fetal monitoring is helpful to recognize any signs of fetal distress. There is consensus that severe hypertension in pregnancy, defined as $>160 / 110 \mathrm{~mm} \mathrm{Hg}$, requires treatment, because these women are at an increased risk of intracerebral hemorrhage, and that treatment decreases the risk of maternal death [22]. Drugs that can be safely used include labetalol (oral or intravenous), nifedipine (oral) and hydralazine (intravenous). The choice should be made depending on the experience of the clinican with a particular agent [23]. Hidralazine is usually administered by intermittent bolus of $5 \mathrm{mg}$ intravenously or intramuscularly. A continuous infusion of $0.5-10.0 \mathrm{mg} . \mathrm{h}$ ) 1 is also typically employed in more refractory cases [24].

Labetolol is usually administered 10 to $20 \mathrm{mg} I \mathrm{~V}$, then 20 to $80 \mathrm{mg}$ every 20 minutes, a continous infusion dosage 1 to $2 \mathrm{mg} / \mathrm{min}$ recommended. Nifedipine is recommended by oral route only 10 to 30 $\mathrm{mg}$ PO, repeat in 45 minutes if needed. Diazoxide is usually administered 30 to $50 \mathrm{mg}$ IV every 5 to 15 minutes. Sodium nitroprusside is rarely used in pregnancy and has known maternal adverse effects of hypotension and paradoxical bradycardia in women with severe preeclampsia. Fetal cyanide toxicity is a complication of prolonged treatment. Sodium nitroprusside should be used with extreme caution in situations of life-threatening hypertension, immediately before delivery in circumstances where clinicians are familiar with its use [22].

\section{Seizure Prophylaxis}

Magnesium sulphate with a loading dose of 4-6 g followed by continuous infusion of $1-2 \mathrm{~g} / \mathrm{h}$ is recommended as prophylaxis for eclampsia. The Magpie Trial previously demonstrated that the risk of respiratory depression is low, even if magnesium therapy is monitored with clinical signs such as deep tendon reflexes and respiratory rate in the absence of plasma level measurements [25]. The prolongation effect of high doses magnesium on nondepolarizing muscle relaxants should be kept in mind.

\section{Platelet Transfusions}

A significant decrease in platelet numbers may be associated with abnormal bleeding. It is recommended that platelet counts should not be allowed to decrease below $50 \times 103$ in the acutely bleeding pregnant woman [26]. 
Single cases indicate that plasmapheresis seems to be a treatment with low risk during pregnancy and could be a promising treatment option for otherwise refractory preeclampsia [27-29].

Deile et al. [30] recommended only use this therapy in specialized centers with first class experience and when performing plasmapheresis in preeclampsia measures to respond to blood pressure drops must always be available and vital signs must be controlled during and after the entire session. This includes continuous electronic foetal heart rate monitoring and cardiovascular monitoring of the mother.

\section{Neuroaxial Anesthesia}

Historically, a common belief about the spinal anesthesia in patients with severe preeclampsia is causing severe hypotension and decreasing uteroplacental perfusion which prevents the widespread use of spinal anesthesia in preeclampsia. After recent studies, comparing general and regional anesthesia risk-benefit considerations strongly favor neuraxial techniques over general anesthesia for cesarean delivery in the setting of severe preeclampsia as long as neuraxial anesthesia is not contraindicated $[31,32]$. Two small prospective studies by Wallace et al. [33] and Sharwood-Smith et al. [34] have shown that the hemodynamic effects of spinal anesthesia were similar to those seen with epidural anesthesia in severely preeclamptic patients; Visalyaputra et al. [35] have shown that the incidence of hypotension was more frequent in the spinal group than in the epidural group (51\% versus $23 \%$ ) in a large population. But they also showed hypotension was easily treated in all patients. They conclude that the results of this large prospective study support the use of spinal anesthesia for cesarean delivery in severely preeclamptic patients.

Berends et al. [36] conducted a prospective trial among 30 patients whom were randomised into three groups: epidural anesthesia with prophylactic fluid loading (EA-F), combined spinal epidural anesthesia with prophylactic fluid loading (CSE-F), or combined spinal epidural anesthesia with prophylactic ephedrine (CSE-V). They concluded that combined spinal and epidural anesthesia (CSE) is a safe alternative to conventional epidural anesthesia in severe preeclamptic women and that the prophylactic use of ephedrine is effective and safe to prevent and treat spinal hypotension after combined spinal and epidural anesthesia for Cesarean section in severe preeclamptic women. However, the small study sample means that the conclusions from this study should be viewed with caution.

Karinen et al. [37] studied a prophylactic crystalloid bolus before spinal anesthesia in preeclamptic patients mean central venous pressure increased significantly after preload, but decreased to baseline shortly after induction of spinal anesthesia. Visalyaputra et al. [35] and Sharwood-Smith et al. [34] showed the transient impact of IV fluid boluses on CVP. Prophylactic phenylephrine infusions have not been studied in the setting of uteroplacental insufficiency, and there is insufficient evidence to suggest their evidence-based use in the preeclamptic population [31].

An important absolute contraindication for neuroaxial anesthesia is coagulation disorders. As discussed earlier preeclampsia is commonly responsible for thrombocytopenia occurring in the 2nd and 3rd trimester. Sharma et al. [38] used thromboelastography and showed that platelet count $>100 \times 103 / \mathrm{mm}^{3}$ there were no abnormalities of coagulation detectable. They also concluded severe preeclamptic women with a platelet count $<100,000 / \mathrm{mm}^{3}$ are hypocoagulable when compared to healthy pregnant women and other preeclamptic women.
Orlikowski et al. [39] have measured platelet count, bleeding time and thrombelastography (TEG) variables and the correlation between these variables in 49 pregnant patients presenting with pre-eclampsia or eclampsia. They figured out in the patients with severe thrombocytopenia a platelet count of $75 \times 103 / \mathrm{mm}^{3}$ should be associated with adequate haemostasis. Taken together in the absence of other coagulation abnormalities, the risk of haemotoma associated with neuroaxial anaesthesia with platelet counts $>75 \times 103 / \mathrm{mm}^{3}$ is very low. There is no proposed data for a "safe" platelet count. Based on a consensus statement from the AmericanSociety of Regional Anesthesia [40] many anesthesiologists require a platelet count of at least 75,000 or $80,000 / \mu \mathrm{L}$ (and, if the platelet count is $<150,000 / \mu \mathrm{L}$, normal partial thromboplastin $[\mathrm{PTT}]$ and prothrombin $[\mathrm{PT}]$ times) before initiating spinal anesthesia in patients with severe preeclampsia. The ASA practice guidelines advise that "the use of a platelet count may reduce the risk of anesthesia-related complications" in preeclampsia. The Association of Anaesthetists of Great Britain \& Ireland, The Obstetric Anaesthetists' Association Regional Anaesthesia UK evaluated relative risks related to neuroaxial blocks in obstetric patients with abnormalities of coagulation; they formed 4 groups of relative risks in idiopathic trombocytopenic pregnants. They grouped patients with Platelet count $>75 \times 103 / \mathrm{mm}^{3}$ within $24 \mathrm{~h}$ of block in normal risk and platelet count $<75 \times 103 / \mathrm{mm}^{3}$ in increased risk group [41].

As emphasized by practice guidelines from the American Society of Anesthesiologists (ASA) and American College of Obstetricians and Gynecologists (ACOG), neuraxial anesthetic techniques, when feasible, are strongly preferred to general anesthesia for preeclamptic parturients.

\section{General Anesthesia}

Specific indications for general anaesthesia for caesarean section include coagulopathy, pulmonary edema and imminent fetal distress.

Moodley et al. [42] compared retrospectively the outcome of caesarean section under epidural anaesthesia. 66 women fulfilled the criteria of being 'stable'. Of the 66 women, 37 received epidural, 27 general, and 2 spinal anaesthesia. There were no major complications with either general or epidural anaesthesia. Epidural anaesthesia was associated with higher one \pm minute Apgar scores. Authors indicate that both maternal and neonatal outcomes are not affected adversely by the use of epidural anaesthesia in selected cases of eclampsia. When you are considering the use of regional anaesthesia in parturients who have had an eclamptic seizure you have to determine the signs or symptoms of cerebral edema. If cerebral edema is present, regional anaesthesia is not recommended [43].

General anesthesia has some dangers in preeclamptic patients. Tracheal intubation may be difficult due to mucosal edema in oral cavity and glottis. Low diameter endotracheal tube had a guide in it should be readied for intubation. Intubation during the shallow anesthesia can cause serious response in systemic and pulmonary arterial hypertension [7]. Alfentanil, fentanyl, remifentanyl, $\mathrm{MgSO}_{4}$, lidocaine, esmolol, nitroglycerine have been used to ablate the hypertensive response to intubation [44] Induction agents with sympathomymetic activity (eg ketamin) should be avoided [7] Emergence from anaesthesia should be handled carefully to avoid hypertension, aspiration and acute pulmonary edema [44]. 


\section{Monitorization Options}

Blood pressure measurement should be done carefully and correctly. Intra-arterial blood pressure measurement enables continuous blood pressure recording, facilitates repeated blood sampling shows cardiac output by minimally invasive cardiac output monitors [44]. Transthoracic echocardiography provides structural and functional information about cardiac performance, diastolic function, and responses to interventions [45-47].

American College of Obstetricians and Gynecologists (ACOG) listed invasive monitorization indications in obstetric patients as follows [7]:

1. Septic patients with refractory hypotension and/or oliguria

2. Unexplained or refractory pulmonary edema or persistant oliguria

3. Gestational hypertension with pulmonary edema or oliguria

4. Cardiovascular decompansation intraoperatively

5. Massive blood or volüme lost or replacement

6. ARDS

7. Shock with unknown etiology

8. New York Heart Association Class III or IV cardiac disease

9. Perioperative or peripartum coronary artery disease.

\section{Analgesia for Labour}

In preeclampsia epidural anesthesia for delivery reduces circulating catecholamine levels and increases plasental perfusion. To start, hydration with $0.5-1 \quad 1$ of crystalloid is necessary. Maternal electrocardiogram, blood pressure, as well as fetal heart rate should be monitored continuously. Administration of oxygen with a facemask or nasal cannula is beneficial. Among the local anesthetics, a low concentration of bupivacaine, $0.125 \%$, with $2 \mu \mathrm{g} / \mathrm{ml}$ of fentanyl as an initial bolus provides excellent analgesia with minimal motor block. Lesser the motor block, greater the benefits with regard to fetal head rotation [48]. In addition the presence of a functioning epidural catheter enables the use of the epidural catheter for titrating local anaesthetic to ensure surgical anaesthesia if delivery turns to cesarean section [49].

\section{Critical Care}

Potential maternal life-threatening complications include cerebral infarction or hemorrhage, congestive heart failure or pulmonary edema, renal failure, or death. Maternal outcome is usually good in those with only isolated hypertension or preeclampsia, whereas it is poor with pheochromocytoma, stroke, thrombotic thrombocytopenic purpura/hemolytic uremic syndrome and with delayed diagnosis and inadequate control of persistent severe hypertension [50].

\section{Acute Pulmonary Edema}

Pulmonary edema refers to an excessive accumulation of fluid in the pulmonary interstitial and alveolar spaces. It may develop in up to $2.9 \%$ of pregnancies complicated by preeclampsia [51].

Oxygen supplementation either via non-invasive ventilation devices or intubation and ventilation are used depending on the severity of the respiratory compromise. Morphine sulfate should be administered intravenously at a dose of 2 to $5 \mathrm{mg}$ to reduce the adrenergic vasoconstrictor stimuli to the pulmonary arteriolar and venous beds.
Furosemide administered intravenously to promote diuresis. Head elevation should also be used [52].

Pulmonary edema may occur $30 \%$ of cases with preeclampsia in the antenatal period [52]. In addition to the therapy discussed above, a multidisciplinary careful decision about delivery should be done with new-born specialists.

\section{Oliguria and Acute Renal Failure}

Oliguria in the postpartum period may occur in the partriurent who has normal renal functions.

Steyn et al. [53] assessed the effects of low dose dopamine for oliguria in severe eclampsia. It is suggested that dopamine should first be tested in non-pregnant women with very low urine output before it is considered for trials with pregnant women because of the potential for severe adverse effects if the dose is exceeded.

Prerenal and intrarenal pathology (acute tubular necrosis) accounts for $83-90 \%$ of all cases of acute renal failure in preeclampsia $[54,55]$. Renal damage secondary to these pathologic changes is seen most commonly in preeclampsia and usually resolves completely after delivery.

The management of acute renal failure in the setting of preeclampsia should focus on reversible conditions as dehydration. Blood pressure control, correcting fluid and electrolyte imbalance, and maintaining adequate nutrition is supportive. Persistent acidemia, hyperkalemia, volüme overload and uraemia are indications for renal replacement therapy [44].

\section{Cerebral Hemorrhage and Stroke}

Cerebral hemorrhage has been reported to be the most common cause of death in patients with eclampsia [56,57]. Stroke is known to be the most common cause of death (45\%) in women with HELLP syndrome who receive traditional nonsteroid obstetric and medical management [58]. Hypertension may persist in the postpartum period. These patients deserve immediate and special attention in intensive care units and antihypertensive therapy to reduce their risk of such neurological events.

\section{Postpartum Plasmapheresis in Severe Preeclampsia}

Scwartz et al. reported a case of severe preeclampsia in which hemolysis and rapid platelet consumption persisted after delivery. Exchange plasmapheresis with fresh frozen plasma were begun on the eighth postpartum day, but the hemolysis and rapid platelet consumption did not begin to improve until the 12th postpartum day. The authors proposed the use of plasmapheresis in highly selected cases of severe preeclampsia with hemolysis and thrombocytopenia that do not resolve after delivery [59]. In 1986 fourteen cases of plasmapheresis with fresh frozen plasma for maternal indications in selected cases of preeclampsia and eclampsia were reviewed and the possible role of plasmapheresis in treating the selested cases is emphasized [60].

Martin et al. [61] assessed the postpartum use of plasma exchange with fresh-frozen plasma in a group of seven women with severe preeclampsia-eclampsia and HELLP syndrome that persisted $<72$ hours after delivery. Within 48 hours of exchange plasmapheresis, they achieved a decreasing trend in lactate dehydrogenase levels and platelet counts increased 4.5 times after 72 hours. 
Katz et al. [62] proposed plasma exchange as a therapeutic option when clinical deterioration occurs due to microangiopathic disease.

There is no animal model based study about this issue. Consequently more studies has to be done on this field [30].

\section{Conclusion}

For patients with preeclampsia an anaesthesist should be aware of the following:

1. Preoperative assesment of the preeclamptic patient involves fluid balance, hemodynamic situation, coagulation profile and careful airway examination

2. Neuraxial anesthetic techniques, when feasible, are strongly preferred to general anesthesia for preeclamptic parturients

3. Tracheal intubation may be difficult due to mucosal edema. Difficult airway management devices should be readied for intubation. Adequate sedation and analgesia is needed to control the stress response to intubation

4. Emergence from anaesthesia should be handled carefully to avoid hypertension, aspiration and acute pulmonary edema.

5. Invasive monitoring for guiding succesful fluid management are supportive

6. Multiple organ failure can be prevented by obsevation of high risk severe preeclamptic patients in intensive care unit setting in antenatal and postnatal period.

\section{References}

1. Khan KS, Wojdyla D, Say L, Gülmezoglu AM, Van Look PF (2006) WHO analysis of causes of maternal death: a systematic review. Lancet 367: 1066-1074.

2. Lewis G (2007) The Confidential Enquiry into Maternal and Child Health (CEMACH). Saving Mothers Lives: Reviewing Maternal Deaths to Make Motherhood Safer. The Seventh report on Confidential Enquiries into Maternal Deaths in the United Kingdom. London: CEMACH.

3. Cantwell R, Clutton-Brock T, Cooper G, Dawson A, Drife J, et al. (2011) Saving Mothers' Lives: Reviewing maternal deaths to make motherhood safer: 2006-2008. The Eighth Report of the Confidential Enquiries into Maternal Deaths in the United Kingdom. BJOG 118 Suppl 1: 1-203.

4. Pattinson RC (2007) Saving mothers. Third report on confidential enquiries into maternal deaths in South Africa, 2002-2004. Pretoria, South Africa: Department of Health.

5. Cunningham FG, Leveno KJ, Bloom SL, Hauth JC, Rouse DJ, et al. (2010) Williams Obstetrics. Pregnancy hypertension. (23rdedn) Chap. 34, New York: McGraw-Hill 706-756.

6. Chestnut DH (2009) Obstetric Anesthesia: Principles and Practice. 4: Philadelphia: Elsevier Mosby 976-982.

7. Sahin S (2006) Hypertension in pregnancy and preeclampsia. Painless Labour and anaesthesia in cesarean section. (1stedn) Bursa: Nobel\&Gunes 133-144.

8. Steegers EA, von Dadelszen P, Duvekot JJ, Pijnenborg R (2010) Preeclampsia. Lancet 376: 631-644.

9. Bosio PM, McKenna PJ, Conroy R (1999) Maternal Central Hemodynamics in Hypertensive Disorders of Pregnancy. Obstetrics \& Gynecology 94: 978-984.

10. Valensise H, Vasapollo B, Gagliardi G, Novelli GP (2008) Early and late preeclampsia: two different maternal hemodynamic states in the latent phase of the disease. Hypertension 52: 873-880.

11. Barton JR, Sibai BM (1991) Cerebral pathology in eclampsia. Clin Perinatol 18: 891-910.

12. Wagner S, Acquah L, Lindell E, Craici I, Wingo M (2011) Posterior reversible encephalopathy syndrome (PRES) and eclampsia: pressing the case for more agressive blood pressure control. Mayo Clinic Proceedings. 86: 851-856.

13. Villa PM, Kajantie E, Räikkönen K, Pesonen AK, Hämäläinen E, et al. (2013) Aspirin in the prevention of pre-eclampsia in high-risk women: a randomised placebo-controlled PREDO Trial and a meta-analysis of randomised trials. BJOG 120: 64-74.

14. Publications Committee, Society for Maternal-Fetal Medicine, Sibai BM (2011) Evaluation and management of severe preeclampsia before 34 weeks' gestation. Am J Obstet Gynecol 205: 191-198.

15. Vigil-De Gracia P, Ortega-Paz L (2012) Pre-eclampsia/eclampsia and hepatic rupture. Int J Gynaecol Obstet 118: 186-189.

16. Moran P, Lindheimer MD, Davison JM (2004) The renal response to preeclampsia. Semin Nephrol 24: 588-595.

17. Dyer RA, Piercy JL, Reed AR (2007) The role of the anaesthetist in the management of the pre-eclamptic patient. Curr Opin Anaesthesiol 20: 168-174.

18. Plaat F, Wray S (2008) Role of the anaesthetist in obstetric critical care. Best Pract Res Clin Obstet Gynaecol 22: 917-935.

19. Hennessy A, Thornton CE, Makris A (2007) A randomised comparison of hydralazine and mini-bolus diazoxide for hypertensive emergencies in pregnancy: the PIVOT trial. Australia and New Zealand Journal of Obstetrics and Gynaecology 47:279-285.

20. Sibai BM, Barton JR (2007) Expectant management of severe preeclampsia remote from term: patient selection, treatment, and delivery indications. Am J Obstet Gynecol 196: 514.

21. Podymow T, August P (2008) Update on the use of antihypertensive drugs in pregnancy. Hypertension 51: 960-969.

22. Duley L, Henderson-Smart DJ, Meher S. (2006) Drugs for treatment of very high blood pressure during pregnancy. Cochrane Database of Systematic Reviews 3: CD001449.

23. National Collabourating Centre for Womenâ $€^{\mathrm{Tw}} \mathrm{s}$ and Childrenâ $€^{\mathrm{Tw}} \mathrm{s}$ Health. (2011) Hypertension in pregnancy. The management of hypertensive disorders during pregnancy. National Institute for Health and Clinical Excellence Guideline 107. August 2010 revised reprint January 2011 ed. London: RCOG, 2011.

24. Altman D, Carroli G, Duley L, Farrell B, Moodley J, et al. (2002) Do women with pre-eclampsia, and their babies, benefit from magnesium sulphate? The Magpie Trial: a randomised placebo-controlled trial. Lancet 359: 1877-1890.

25. Olagundoye V, MacKenzie IZ (2007) The impact of a trial of instrumental delivery in theatre on neonatal outcome. BJOG 114: 603-608.

26. Frampton G, Cameron JS, Thom M, Jones S, Raftery M (1987) Successful removal of anti-phospholipid antibody during pregnancy using plasma exchange and low-dose prednisolone. Lancet 2: 1023-1024

27. Seyyed Majidi MR, Vafaeimanesh J (2013) Plasmapheresis in acute Fatty liver of pregnancy: an effective treatment. Case Rep Obstet Gynecol 2013: 615975.

28. Jin F, Cao M, Bai Y, Zhang Y, Yang Y, et al. (2012) Therapeutic effects of plasma exchange for the treatment of 39 patients with acute fatty liver of pregnancy. Discov Med 13: 369-373.

29. Müller-Deile J, Schiffer M (2014) Preeclampsia from a renal point of view: Insides into disease models, biomarkers and therapy. World J Nephrol 3: 169-181.

30. Henke VG, Bateman BT, Leffert LR (2013) Focused review: spinal anesthesia in severe preeclampsia. Anesth Analg 117: 686-693.

31. Hood DD, Curry R (1999) Spinal versus epidural anesthesia for cesarean section in severely preeclamptic patients: a retrospective survey. Anesthesiology 90: 1276-1282.

32. Wallace DH, Leveno KJ, Cunningham FG (1995) Randomized comparison of general and regional anesthesia for cesarean delivery in pregnancies complicated by severe preeclampsia. Obstet Gynecol 86:193-199.

33. Sharwood-Smith G, Clark V, Watson E (1999) Regional anaesthesia for caesarean section in severe preeclampsia: spinal anaesthesia is the preferred choice. Int J Obstet Anesth 8:85-89. 
34. Visalyaputra S, Rodanant O, Somboonviboon W, Tantivitayatan K, Thienthong S, et al. (2005) Spinal versus epidural anesthesia for cesarean delivery in severe preeclampsia: a prospective randomized, multicenter study. Anesth Analg 101: 862-868, table of contents.

35. Berends N, Teunkens A, Vandermeersch E, Van de Velde M (2005) A randomized trial comparing low-dose combined spinal-epidural anesthesia and conventional epidural anesthesia for cesarean section in severe preeclampsia. Acta Anaesthesiol Belg 56: 155-162.

36. Karinen J, Räsänen J, Alahuhta S, Jouppila R, Jouppila P (1996) Maternal and uteroplacental haemodynamic state in pre-eclamptic patients during spinal anaesthesia for Caesarean section. Br J Anaesth 76: 616-620.

37. Sharma SK, Philip J, Whitten CW, Padakandla UB, Landers DF (1999) Assessment of changes in coagulation in parturients with preeclampsia using thromboelastography. Anesthesiology 90: 385-390.

38. Orlikowski CE, Rocke DA, Murray WB, Gouws E, Moodley J, et al. (1996) Thrombelastography changes in pre-eclampsia and eclampsia. $\mathrm{Br} \mathrm{J}$ Anaesth 77: 157-161.

39. Horlocker TT, Wedel DJ, Rowlingson JC, Enneking FK, Kopp SL, et al. (2010) Regional anesthesia in the patient receiving antithrombotic or thrombolytic therapy: American Society of Regional Anesthesia and Pain Medicine Evidence-Based Guidelines (Third Edition). Reg Anesth Pain Med 35: 64-101.

40. Working Party (2013) Association of Anaesthetists of Great Britain \& Ireland; Obstetric Anaesthetists' Association; Regional Anaesthesia UK.

41. Regional anaesthesia and patients with abnormalities of coagulation: the Association of Anaesthetists of Great Britain \& Ireland The Obstetric Anaesthetists' Association Regional Anaesthesia UK. Anaesthesia 68: 966-972

42. Moodley J, Jjuuko G, Rout C (2001) Epidural compared with general anaesthesia for caesarean delivery in conscious women with eclampsia. BJOG 108: 378-382.

43. Dyer RA, Piercy JL, Reed AR (2007) The role of the anaesthetist in the management of the pre-eclamptic patient. Curr Opin Anaesthesiol 20: 168-174.

44. Dennis AT (2012) Management of pre-eclampsia: issues for anaesthetists. Anaesthesia 67: 1009-1020.

45. Regitz-Zagrosek V, Lundqvist CB, Borghi C (2011) European Society of Cardiology Guidelines on the management of cardiovascular diseases during pregnancy: the Task Force on the Management of Cardiovascular Diseases during Pregnancy of the European Society of Cardiology (ESC). European Heart Journal 32: 3147-3197

46. American College of Cardiology Foundation Appropriate Use Criteria Task Force; American Society of Echocardiography; American Heart Association; American Society of Nuclear Cardiology; Heart Failure Society of America; Heart Rhythm Society; Society for Cardiovascular Angiography and Interventions; Society of Critical Care Medicine; Society of Cardiovascular Computed Tomography; Society for Cardiovascular Magnetic Resonance; American College of Chest Physicians, Douglas PS, Garcia MJ, Haines DE, Lai WW, et al. (2011) ACCF/ASE/AHA/ASNC/HFSA/HRS/SCAI/SCCM/SCCT/SCMR 2011 Appropriate Use Criteria for Echocardiography. A Report of the American College of Cardiology Foundation Appropriate Use Criteria Task Force, American Society of Echocardiography, American Heart
Association, American Society of Nuclear Cardiology, Heart Failure Society of America, Heart Rhythm Society, Society for Cardiovascular Angiography and Interventions, Society of Critical Care Medicine, Society of Cardiovascular Computed Tomography, Society for Cardiovascular Magnetic Resonance American College of Chest Physicians. J Am Soc Echocardiogr 24: 229-267.

47. Dennis AT (2011) Transthoracic echocardiography in obstetric anaesthesia and obstetric critical illness. International Journal of Obstetric Anesthesia 20: 166-168.

48. Parthasarathy S, Kumar VR, Sripriya R, Ravishankar M (2013) Anesthetic management of a patient presenting with eclampsia. Aneshesia:Essays and Researchs 7: 307-312.

49. Newsome LR, Bramwell RS, Curling PE (1986) Severe preeclampsia: hemodynamic effects of lumbar epidural anesthesia. Anesth Analg 65: 31-36.

50. Sibai BM (2012) Etiology and management of postpartum hypertensionpreeclampsia. Am J Obstet Gynecol 206: 470-475.

51. Sibai BM, Mabie BC, Harvey CJ (1987) Pulmonary edema in severe preeclampsiaeclampsia: Analysis of thirty-seven consecutive cases. Am J Obstet Gynecol. 156: 1174-1179.

52. Norwitz ER, Hsu CD, Repke JT (2002) Acute complications of preeclampsia. Clin Obstet Gynecol 45: 308-329.

53. Steyn DW, Steyn P (2007) Low-dose dopamine for women with severe pre-eclampsia. Cochrane Database Syst Rev: CD003515.

54. Sibai BM, Villar MA, Mabie BC (1990) Acute renal failure in hypertensive disorders of pregnancy. Pregnancy outcome and remote prognosis in thirty-one consecutive cases. Am J Obstet Gynecol 162: 777-783.

55. Rodríguez González D, Godina Gallardo M, Hernández Chávez A, Ramírez García A, Hernández Camarena R (1998) [Severe pre-eclampsia, HELLP syndrome and renal failure]. Ginecol Obstet Mex 66: 48-51.

56. Okanloma KA, Moodley J (2000) Neurological complications associated with the pre-eclampsia/eclampsia syndrome. Int J Gynaecol Obstet 71: 223-225.

57. Moodley J (1997) Preeclampsia/eclampsia syndrome. S Afr J Contin Med Educ 15:31-41

58. Isler CM, Rinehart BK, Terrone DA, Martin RW, Magann EF, Martin JN Jr (1999) Maternal mortality associated with HELLP (hemolysis, elevated liver enzymes, and low platelets) syndrome. Am J Obstet Gynecol 181: 924-928.

59. Schwartz ML, Brenner W (1985) Severe preeclampsia with persistent postpartum hemolysis and thrombocytopenia treated by plasmapheresis. Obstet Gynecol 65: 53S-55S

60. Schwartz ML (1986) Possible role for exchange plasmapheresis with fresh frozen plasma for maternal indications in selected cases of preeclampsia and eclampsia. Obstet Gynecol 68: 136-139

61. Martin JN Jr, Files JC, Blake PG, Norman PH, Martin RW, et al. (1990) Plasma exchange for preeclampsia. I. Postpartum use for persistently severe preeclampsia-eclampsia with HELLP syndrome. Am J Obstet Gynecol 162: 126-137.

62. Katz VL, Watson WJ, Thorp JM Jr, Hansen W, Bowes WA Jr (1992) Treatment of persistent postpartum HELLP syndrome with plasmapheresis. Am J Perinatol 9: 120-122. 